\title{
The Role of Gastroesophageal Reflux in Relation to Symptom Onset in Patients with Proton Pump Inhibitor-Refractory Nonerosive Reflux Disease Accompanied by an Underlying Esophageal Motor Disorder
}

\author{
Shinya Izawa ${ }^{a}$ Yasushi Funaki ${ }^{a}$ b Akihito lida $^{a}$ Kentaro Tokudome ${ }^{a}$ \\ Yasuhiro Tamura $^{a}$ Naotaka Ogasawara ${ }^{a}$ Makoto Sasaki ${ }^{a}$ Kunio Kasugai ${ }^{a}$ \\ ${ }^{a}$ Department of Internal Medicine, Division of Gastroenterology, and ${ }^{\mathrm{b}}$ Department of Clinical Laboratory, \\ Aichi Medical University School of Medicine, Nagakute, Japan
}

\author{
Key Words \\ Esophageal motility disorder - Frequency Scale for the \\ Symptoms of GERD · Manometry · Nonerosive reflux \\ disease $\cdot$ Multichannel intraluminal impedance-pH \\ monitoring
}

\begin{abstract}
Background: The symptom improvement rate is low with proton pump inhibitors (PPIs) in nonerosive reflux disease (NERD). The underlying pathogenic mechanism is complex. Esophageal motility disorders (EMDs) are thought to be a factor, but their prevalence, type, symptoms and the role played by gastroesophageal reflux (GER) in symptom onset have not been fully investigated. Aim: To investigate the role of GER in symptom onset in PPI-refractory NERD patients with EMDs. Methods: This study comprised 76 patients with PPI-refractory NERD. Manometry was performed during PPI treatment and patients were divided into an EMD group and normal motility (non-EMD) group. Then, multichannel intraluminal impedance-pH monitoring was performed and medical interviews were conducted. Results: Nineteen patients (25\%) had an EMD. Data were compared between 17 patients, excluding 2 with achalasia and 57 non-EMD patients. No significant differences were observed between groups in 24-
\end{abstract}

hour intraesophageal $\mathrm{pH}<4$ holding time $(\mathrm{HT})$, mean number of GER episodes or mean number of proximal reflux episodes. The reflux-related symptom index $(\geq 50 \%)$ showed a relationship between reflux and symptoms in $70.5 \%$ of EMD patients and $75 \%$ of non-EMD patients. In the EMD group, the score for FSSG (Frequency Scale for the Symptoms of GERD) question (Q) 10 was significantly correlated with the number of GER episodes $(r=0.58, p=0.02)$ and the number of proximal reflux episodes $(r=0.63, p=0.02)$. In addition, the score for Q9 tended to be correlated with the number of GER episodes $(r=0.44, p=0.06)$. Conclusion: Our results suggest that some PPI-refractory NERD patients have EMDs, and that GER plays a role in symptom onset.

(c) 2014 S. Karger AG, Basel

\section{Introduction}

Gastroesophageal reflux disease (GERD) is defined as a condition in which the reflux of stomach contents causes troublesome symptoms and/or complications [1]. Morphological factors involved in gastroesophageal reflux (GER) include motility disorders, esophageal hiatal hernia, decreased lower esophageal sphincter (LES) pressure, transient LES relaxation and increased intra-ab-

\section{KARGER}

E-Mail karger@karger.com www.karger.com/dig
(C) 2014 S. Karger AG, Basel

0012-2823/14/0891-0061\$39.50/0
Yasushi Funaki, MD, PhD

Department of Gastroenterology

Aichi Medical University School of Medicine

1-1 Yazakokarimata, Nagakute, Aichi 480-1195 (Japan)

E-Mail momomaru@aichi-med-u.ac.jp 
Table 1. Manometric criteria for EMDs [12]

\begin{tabular}{ll}
\hline Esophageal disorder & Manometric criteria \\
\hline Hypertensive LES & LES pressure $>45 \mathrm{~mm} \mathrm{Hg}$ \\
Ineffective esophageal disorder & Distal amplitude $<30 \mathrm{~mm} \mathrm{Hg}$ \\
& $>30 \%$ nontransmitted swallows \\
Nonspecific esophageal disorder & Esophageal body \\
& Nontransmitted peristalsis $(>20 \%)$ \\
& Triple peaked waves \\
& Retrograde duration contraction (mean $>6 \mathrm{~s})$ \\
& LES pressure \\
& Residual $>5 \mathrm{~mm} \mathrm{Hg}$ \\
\hline
\end{tabular}

dominal pressure [2]. On the other hand, nonerosive reflux disease (NERD) [1] is a functional gastrointestinal disorder that is defined as being present when, despite typical symptoms of GER such as heartburn and acid regurgitation, upper endoscopy reveals no gastroesophageal mucosal abnormalities.

NERD accounts for at least half of GERD cases [3], but acid reflux has little role in the pathogenic mechanism [4], and with proton pump inhibitors (PPIs), which are the first choice of treatment in GERD $[5,6]$, the symptom improvement rate in NERD is low [3,7-9]. In the pathogenesis of PPI-refractory NERD, which occurs in $\geq 50 \%$ of NERD patients, other than acidity, nonacid reflux, abnormal esophageal motility, esophageal hypersensitivity and psychological factors are intricately related [10].

This study included PPI-refractory NERD patients in whom symptoms did not improve with a PPI, the first choice of treatment for GERD. In these patients with socalled functional heartburn, the prevalence, types and symptoms of EMDs were evaluated, and the relationship between GER and symptom onset was examined.

\section{Methods}

\section{Subjects}

This was a prospective study conducted at Aichi Medical University Hospital. From the group of NERD patients who complained of heartburn at least twice a week and who were found to have no organic abnormalities (excluding esophageal hiatus hernia) on upper gastrointestinal endoscopy, patients whose heartburn symptoms did not improve despite taking a PPI at the standard dose for at least 8 weeks (PPI-refractory NERD patients) were targeted. A total of 76 patients ( 44 males, 32 females; mean age $54.8 \pm 1.7$ years; mean BMI $22.4 \pm 0.4$ ) examined by the Department of Gastroenterology, Aichi Medical University Hospital, were enrolled between January 2007 and March 2012. The study was approved by the Ethics Committee of Aichi Medical University School of Medicine and performed with the written informed consent of the patients. All medical interviews and examinations were conducted while patients were taking a continuous course of PPI at standard doses.

\section{Manometric Study}

Intraesophageal pressure was tested using a Polygraf ID multiparameter gastrointestinal motility function measurement system (Sierra Scientific Instruments, Los Angeles, Calif., USA) with an 8-channel, water-perfused, Dent's sleeve catheter inserted nasally into the esophagus. The LES position from the nasal cavity, LES pressure and primary peristaltic wave based on 10 water swallows were observed with the patient recumbent. Esophageal motility disorders (EMDs) were classified as achalasia, diffuse esophageal spasm, nutcracker esophagus, hypertensive LES, ineffective esophageal motility (IEM) [11] and nonspecific EMDs, following the classification of Castell et al. [12] (table 1).

\section{4-Hour Multichannel Intraluminal Impedance-pH}

Monitoring

The multichannel intraluminal impedance-pH (MII-pH) monitoring system (Sleuth ${ }^{\circledR}$ multi-impedance $\mathrm{pH}$ monitoring system, Sandhill Scientific, Highlands Ranch, Colo., USA) [13] included a portable data logger with impedance-pH amplifiers and a catheter with one antimony $\mathrm{pH}$ electrode and eight impedance electrodes at 2, 4, 6, 8, 10,14, 16 and $18 \mathrm{~cm}$ from the tip of the catheter. Each pair of adjacent electrodes represented an impedancemeasuring segment (length $2 \mathrm{~cm}$ ) corresponding to one recording channel. The six impedance and one $\mathrm{pH}$ signals were recorded at $50 \mathrm{~Hz}$ on a $128-\mathrm{MB}$ CompactFlash (SanDisk, Milpitas, Calif., USA). The single-use MII-pH catheter was passed into the esophagus transnasally and positioned with the $\mathrm{pH}$ electrode $5 \mathrm{~cm}$ above the upper margin of the LES, and data were continuously recorded for 24 hours while the patient remained in hospital. Proximal extent (number and percent of reflux episodes reaching $15 \mathrm{~cm}$ above LES) was also measured.

Patients ate three meals and were asked to record their posture (e.g. recumbent), meals and occurrence of heartburn and other symptoms. Data analysis excluding mealtimes was done using BioVIEW Analysis ${ }^{\circledR}$ computer software (version 5.3.4, Sandhill Scientific). This analytical software is capable of automatically evaluating parameters such as reflux frequency of liquid and gas, and mixtures of the two, $\mathrm{pH}$ of liquids, and symptom indices (SI) of these parameters with a high degree of reliability [14]. SI was defined as positive if the proportion of symptoms due to reflux accounted for at least $50 \%$ of overall symptoms in $24 \mathrm{~h}$ [15].

\section{Medical Interview}

During examination, reflux symptoms were assessed using the questionnaire for the Frequency Scale for the Symptoms of GERD 
(FSSG) [16]. The FSSG total score and acid reflux [question (Q)1, 4, $6,7,9,10,12]$, motility disorder $(\mathrm{Q} 2,3,5,8,11)$ and laryngopharyngeal reflux (LPR; total of Q7 + 9) scores were evaluated. To check for the presence of neuroticism, patients were also asked to complete the Cornell Medical Index (CMI) [17] questionnaire which has been widely used as a method of psychiatric case identification.

\section{Statistical Analysis}

Data are shown as means \pm standard deviation. Analysis was based on the Mann-Whitney test, Fisher's test, Kruskal-Wallis test and Spearman's rank correlation. A significant difference was defined as $\mathrm{p}<0.05$.

\section{Results}

Based on esophageal manometry in the 76 PPI-refractory NERD patients, 19 (25\%) could be diagnosed as having an EMD. Based on the Rome III diagnostic criteria, excluding 2 patients with achalasia, 17 patients ( 9 men, 8 women; mean age $56.5 \pm 3.4$ years; BMI $23.1 \pm 0.7)$ were classified in the EMD group, including 6 with IEM, 9 with nonspecific EMD and 2 with hypertensive LES (HLES). A total of 57 patients ( 35 men, 22 women; mean age $53.4 \pm$ 16.3 years; BMI $22.2 \pm 2.9$ ) were in the normal motility group without an EMD (non-EMD group; fig. 1).

The CMI showed neuroticism (area III or IV) in 13 patients $(22.8 \%)$ in the non-EMD group and 4 patients $(23.5 \%)$ in the EMD group, but neuroticism, as well as sex, age and BMI, did not differ significantly between the groups (table 2). On 24-hour MII-pH monitoring, the percentage time of 24 -hour intraesophageal $\mathrm{pH}<4$ holding time (HT) was $6.9 \pm 12.3 \%$ in the non-EMD group and $4.7 \pm 2.4 \%$ in the EMD group. Excessive acid reflux was present in 13 patients (22\%) with non-EMD and 3 patients (18\%) with EMD, but no significant difference was found between the groups.

The mean number of GER episodes in the non-EMD group and the EMD group was $59.5 \pm 40.7$ and $80.5 \pm$ 17.9 , respectively, and the mean number of proximal reflux episodes ( $15 \mathrm{~cm}$ above the LES) was $24.2 \pm 20.4$ and $29.3 \pm 9.3$, respectively. No significant differences were observed (table 2). The percentage of reflux contents over $24 \mathrm{~h}$ was acid $11 \%$, nonacid $68 \%$ and gas $21 \%$ in the nonEMD group, and acid $15 \%$, nonacid $63 \%$ and gas $22 \%$ in the EMD group. No significant differences were observed between the groups.

The reflux-related symptom index (SI) was positive (SI $\geq 50 \%)$ in 43 (75\%) of the non-EMD group patients and $12(70.5 \%)$ of the EMD group patients. No significant difference was found. The SI-positive reflux contents in the non-EMD group were as follows: acid only in 7 , nonacid

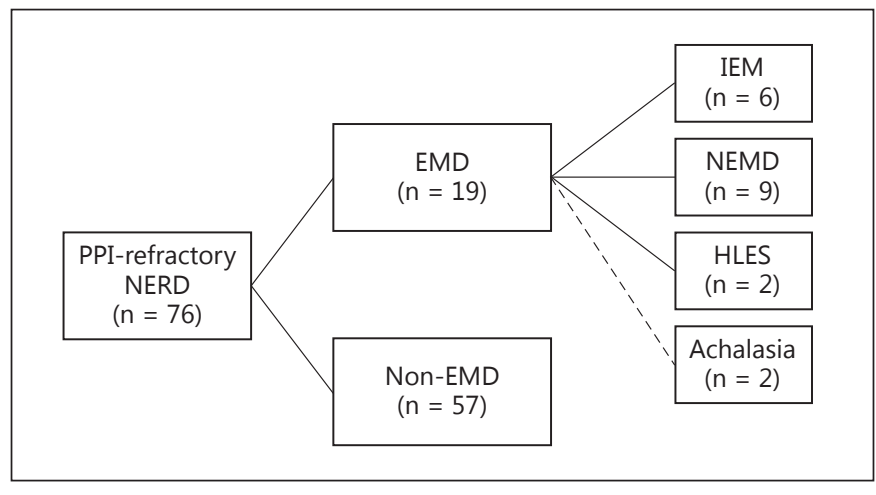

Fig. 1. Classification of PPI-refractory NERD patients by etiology using the intraesophageal pressure test.

only in 14 , gas only in 8 , acid + nonacid in 5 , acid + gas in 2 , nonacid + gas in 5 , and acid + nonacid + gas in 2 patients. Reflux contents in the EMD group were as follows: nonacid in 3 , gas only in 1 , acid + nonacid in 4 , nonacid + gas in 3 , and acid + nonacid + gas in 1 patient (table 2 ).

A comparison of symptoms showed no significant differences in the mean FSSG total score, mean acid reflux score or mean LPR score (table 2). Evaluation of a correlation between each FSSG question and number of reflux episodes showed that, in the non-EMD group patients, there was no correlation with mean number of GER episodes or number of proximal reflux episodes. However, in the EMD group patients, the score for Q10 ['Do you get bitter liquid (acid) coming up into your throat?'] was significantly correlated both with the number of GER episodes and the number of proximal reflux episodes. The score for Q9 ('Do some things get stuck when you swallow?') tended to be correlated with the number of GER episodes (table 3; fig. 2).

\section{Discussion}

In clinical practice, of NERD patients who complain of symptoms despite the absence of structural abnormalities on GI studies including upper endoscopy, when symptoms improve with a trial of PPI therapy, heartburn due to endoscopy-negative reflux disease can be presumptively diagnosed without any clinical problems. On the other hand, in PPI-refractory NERD patients without symptom improvement using an oral PPI, further evaluation including MII-pH monitoring $[18,19]$ and assessment of esophageal motor function such as manometry [20] may be useful. However, since such testing is not always avail- 
Table 2. Comparisons between the non-EMD and EMD groups

\begin{tabular}{|c|c|c|c|}
\hline Characteristics & Non-EMD $(\mathrm{n}=57)$ & $\operatorname{EMD}(\mathrm{n}=17)$ & $\mathrm{p}$ value \\
\hline Age, years & $53.4 \pm 16.3$ & $56.5 \pm 3.4$ & 0.42 \\
\hline Male/female & $35 / 22$ & $9 / 8$ & 0.55 \\
\hline BMI & $22.2 \pm 3.0$ & $23.1 \pm 0.7$ & 0.25 \\
\hline Neuroticism (III or IV) ${ }^{1}$ & $13(22.8)$ & $4(23.5)$ & 0.96 \\
\hline \multicolumn{4}{|c|}{ 24-Hour intraesophageal ambulatory multichannel } \\
\hline 24-Hour intraesophageal time $\mathrm{pH}<4, \%$ & $6.9 \pm 12.4$ & $4.7 \pm 2.4$ & 0.13 \\
\hline Gastroesophageal reflux episodes & $59.5 \pm 40.7$ & $80.5 \pm 17.9$ & 0.86 \\
\hline Proximal reflux episodes & $24.3 \pm 20.4$ & $29.3 \pm 9.3$ & 0.74 \\
\hline \multicolumn{4}{|l|}{ Reflux contents, $\%$} \\
\hline Acid & 11 & 15 & \\
\hline Nonacid & 68 & 63 & \\
\hline Gas & 21 & 22 & \\
\hline SI $\geq 50 \%$ & $43(75.4)$ & $12(70.5)$ & 0.84 \\
\hline Nonacid only & $14(32.6)$ & $3(25)$ & \\
\hline Gas only & $8(18.6)$ & $1(8.3)$ & \\
\hline Acid only & $7(16.3)$ & $0(0)$ & \\
\hline Acid and nonacid & $5(11.6)$ & $4(33.3)$ & \\
\hline Nonacid and gas & $5(11.6)$ & $3(25)$ & \\
\hline Acid and gas & $2(4.7)$ & $0(0)$ & \\
\hline Acid, nonacid and gas & $2(4.7)$ & $1(8.3)$ & \\
\hline \multicolumn{4}{|l|}{ FSSG score } \\
\hline FSSG total score & $17.9 \pm 8.9$ & $17.0 \pm 2.1$ & 0.59 \\
\hline Reflux score & $9.5 \pm 5.8$ & $10.2 \pm 1.2$ & 0.71 \\
\hline LPR & $2.6 \pm 2.2$ & $3.7 \pm 0.5$ & 0.12 \\
\hline
\end{tabular}

Values are either mean \pm standard deviation or number with percentage in parentheses, unless otherwise indicated. $\mathrm{p}$ values compare non-EMD and EMD using the Mann-Whitney test and Fisher's test. Reflux score was calculated with Q1, 4, 6, 7, 9, 10 and 12 on the FSSG. LPR score was calculated with Q10 and 12 on the FSSG.

${ }^{1}$ Defined by the CMI.
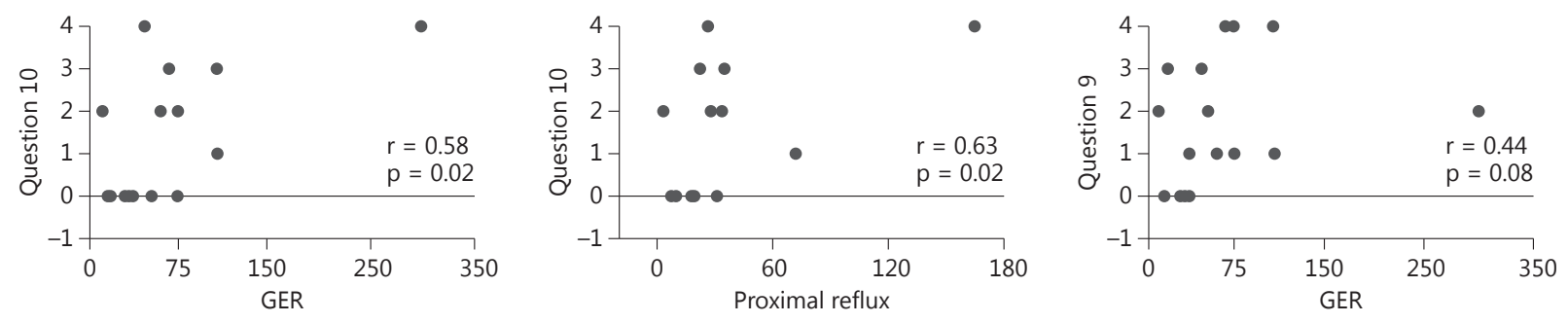

Fig. 2. FSSG questionnaire responses from patients with EMDs. Responses to Q10 of the FSSG were significantly related to the rates of both gastric $(\mathrm{r}=0.58, \mathrm{p}=0.02)$ and proximal reflux $(\mathrm{r}=0.63, \mathrm{p}=0.02)$. Responses to $\mathrm{Q} 9$ of the FSSG were also related to the rate of gastric reflux $(\mathrm{r}=0.44, \mathrm{p}=0.08)$.

able in general medical settings, many patients do not receive further evaluation.

In a study in Japan of 29 endoscopy-negative reflux disease patients refractory to double doses of PPIs, 1 patient was reported with nonspecific EMD [21]. In the present study of 76 PPI-refractory NERD patients, however, 19 (25\%) had an EMD. A comparison between the 17 EMD group patients, excluding two with esophageal achalasia, and the 57 non-EMD group patients showed no significant differences in sex, age, BMI or neuroticism as assessed by
64
Izawa/Funaki/Iida/Tokudome/Tamura/ Ogasawara/Sasaki/Kasugai 
Table 3. Correlation between symptoms on the FSSG and the number of GER episodes

\begin{tabular}{|c|c|c|c|c|}
\hline \multirow[t]{2}{*}{ Question } & \multicolumn{2}{|c|}{$\begin{array}{l}\text { GER episodes } \\
(\text { mean } 59.5 \pm 5.5)\end{array}$} & \multicolumn{2}{|c|}{$\begin{array}{l}\text { Proximal reflux episodes } \\
\text { (mean } 24.2 \pm 5.5)\end{array}$} \\
\hline & $\begin{array}{l}\text { correlation } \\
\text { coefficient }\end{array}$ & $\mathrm{p}$ value & $\begin{array}{l}\text { correlation } \\
\text { coefficient }\end{array}$ & $\mathrm{p}$ value \\
\hline \multicolumn{5}{|l|}{ Non-EMD groups $(n=57)$} \\
\hline 1 Do you get heartburn? & & 0.52 & 0.09 & 0.67 \\
\hline 4 Do you sometimes subconsciously rub your chest with your hand? & 0.09 & 0.58 & 0.05 & 0.83 \\
\hline 5 Do you ever feel sick after meals? & 0.14 & 0.46 & 0.23 & 0.16 \\
\hline 6 Do you get heartburn after meals? & 0.09 & 0.62 & 0.06 & 0.83 \\
\hline 7 Do you have an unusual (e.g. burning) sensation in your throat? & -0.1 & 0.28 & -0.05 & 0.48 \\
\hline 8 Do you feel full while eating meals? & 0.09 & 0.7 & 0.13 & 0.49 \\
\hline \multirow[t]{2}{*}{ Question } & \multicolumn{2}{|c|}{$\begin{array}{l}\text { GER episodes } \\
(\text { mean } 80.5 \pm 17.9)\end{array}$} & \multicolumn{2}{|c|}{$\begin{array}{l}\text { Proximal reflux episodes } \\
\text { (mean } 29.3 \pm 9.3)\end{array}$} \\
\hline & $\begin{array}{l}\text { correlation } \\
\text { coefficient }\end{array}$ & $\mathrm{p}$ value & $\begin{array}{l}\text { correlation } \\
\text { coefficient }\end{array}$ & $\mathrm{p}$ value \\
\hline \multicolumn{5}{|l|}{ EMD groups $(n=17)$} \\
\hline 1 Do you get heartburn? & 0.11 & 0.78 & 0.05 & 0.99 \\
\hline 2 Does your stomach get bloated? & -0.05 & 0.59 & 0.05 & 0.92 \\
\hline 3 Does your stomach ever feel heavy after meals? & 0.17 & 0.56 & 0.18 & 0.56 \\
\hline 4 Do you sometimes subconsciously rub your chest with your hand? & 0.35 & 0.21 & 0.34 & 0.23 \\
\hline 5 Do you ever feel sick after meals? & 0.21 & 0.59 & 0.15 & 0.77 \\
\hline
\end{tabular}

No correlation between each FSSG question and either number of GER episodes or number of proximal reflux episodes was observed in the normal non-EMD group. However, in the EMD group, FSSG Q10 was significantly correlated with the number of GER episodes and proximal reflux episodes, and Q9 tended to be correlated with the number of GER episodes.

the CMI. In addition, LES pressure in HLES patients increases due to various factors such as emotional stress and GER [22]. However, in the present study, 4 (23.5\%) out of 17 patients in the EMD group had neuroticism, but with no significant difference compared to the non-EMD group. Thus, emotional stress was not observed to have a role.

On evaluation of GER using 24-hour MII-pH monitoring, the non-EMD group, similar to the EMD group, had excessive acid reflux into the esophagus despite standard oral doses of PPIs. However, the high dose of PPI treatment may be effective for these non-EMD patients with excessive acid reflux into the esophagus despite standard oral doses of PPI [23]. Excessive acid is a factor in increasing LES pressure in HLES patients [22]. In a study of acid exposure time and esophageal manometry in GERD patients, including 48 patients aged $\leq 40$ years and 133 patients aged $\geq 65$ years, LES pressure decreased in both groups with increased acid exposure time, but the patients aged $\geq 65$ years 
had a higher rate of decreased synchronous peristaltic waves [24]. Another study reported similar rates of IEM irrespective of esophagitis in GERD patients [25].

In a study of frequency of esophageal motor abnormalities in 113 NERD patients and 37 GERD patients, the frequency of IEM was low at $15.9 \%$ in NERD patients, and the frequency of IEM increased with more severe esophageal mucosal lesions [26]. In a study involving $\mathrm{pH}$ monitoring in erosive esophagitis and NERD associated with IEM, no difference in the rate of acid reflux was reported [27]. No differences even with severity of manometric findings have been reported [28]. In addition, in an assessment of IEM patients for an EMD using impedance testing, swallowed bolus transit was normal in $60-70 \%$ of cases of abnormal peristalsis in IEM patients, and in about $1 / 3$ of IEM patients diagnosed by manometry, impedance testing was normal [29]. EMD increased in parallel with the severity of GERD from NERD to erosive esophagitis and Barrett esophagus [30]. These findings in the above reports suggest a very complex relationship between GER and symptom onset in patients with EMDs.

However, in the PPI-refractory NERD patients in the present study, comparison of the non-EMD group and the EMD group showed no significant differences in the 24-hour mean number of GER episodes or proximal reflux episodes, including 24-hour intraesophageal $\mathrm{pH}<4$ (HT). In addition, the SI-positive rate was high in both groups, $75 \%$ in the non-EMD group and $70.5 \%$ in the EMD group, but the difference was not significant. Based on 24-hour MII-pH monitoring in the present study of PPI-refractory NERD patients, GER specifically associated with an EMD could not be detected.

In a study of 100 GERD patients with primary symptoms of LPR, $48 \%$ had IEM, 10\% had HLES, 9\% had a nutcracker esophagus and $4 \%$ had achalasia, but no differences in acid reflux with these motility disorders were reported [31]. In the present study with symptom assessment using the FSSG, no significant differences were observed between the non-EMD group and the EMD group in FSSG total score, acid reflux score or LPR score. Moreover, among the types of EMDs, there were no differences in FSSG total score, acid reflux score or LPR score. Based on the above findings, because clinical characteristics, symptoms and GER dynamics did not differ between the non-EMD group and the EMD group, manometry (measurement of intraesophageal pressure) was necessary to distinguish between these two groups.

In reports to date, no relationship between GER and symptoms in PPI-refractory NERD patients has been found $[10,32]$, and also in the present study no correla- tion between each FSSG question and the number of GER episodes or the number of proximal reflux episodes was observed in the non-EMD group. However, in the EMD group, FSSG Q10 was correlated with the number of GER and proximal reflux episodes, and Q9 tended to be correlated with the number of GER episodes. These results demonstrate that GER, particularly proximal reflux, is important in symptom onset in patients with EMDs who are taking a PPI.

This study had some limitations. First, because the subjects were PPI-refractory NERD patients at a very highly specialized medical institution, this may have introduced a bias in case selection. The number of patients was also limited because of this study being conducted at a single institution. Second, this study targeted patients taking standard PPI doses, which are covered by health insurance in Japan. Therefore, PPI dose and treatment duration must be taken into consideration when comparing the data from other countries.

Irrespective of these limitations, the present study of Japanese patients with PPI-refractory NERD found that a certain percentage of patients have an EMD, and that in these patients with an EMD, GER plays a role in symptom onset. In addition, Q10 and Q9 of the FSSG, which is convenient for questionnaire interview, were useful items in predicting an EMD associated with GER. This can serve as a useful index in deciding indications for further testing of esophageal motor function, which is not universally available at general medical facilities.

In conclusion, some Japanese patients with PPI-refractory NERD have an EMD. Early detection of these patients during general medical care and appropriate testing and treatment can improve patient satisfaction and quality of life.

\section{Acknowledgments}

The authors thank Dr. Kasugai K. Moore for revision of the scientific language. This study was supported in part by Research Organization for Gastro-Enterological Disease Treatment (NPOROGET).

\section{Disclosure Statement}

Kunio Kasugai received research grants from Research Organization for Gastro-Enterological Disease Treatment (NPOROGET) and Daiich Sankyo Co. Ltd., and lecture fees from Daiich Sankyo Co. Ltd. and Astra Zeneca Co. Ltd. All other authors have no conflict of interest to declare.
Izawa/Funaki/Iida/Tokudome/Tamura/ Ogasawara/Sasaki/Kasugai 


\section{References}

-1 Vakil N, van Zanten SV, Kahrilas P, Dent J, Jones R: The Montreal definition and classification of gastroesophageal reflux disease: a global evidence-based consensus. Am J Gastroenterol 2006;101:1900-1920, quiz 1943.

$\checkmark 2$ Kahrilas PJ: Gerd pathogenesis, pathophysiology, and clinical manifestations. Cleve Clin J Med 2003;70(suppl 5):S4-S19.

3 Mishima I, Adachi K, Arima N, Amano K, Takashima T, Moritani M, Furuta K, Kinoshita Y: Prevalence of endoscopically negative and positive gastroesophageal reflux disease in the Japanese. Scand J Gastroenterol 2005;40: 1005-1009.

-4 Fass R: Epidemiology and pathophysiology of symptomatic gastroesophageal reflux disease. Am J Gastroenterol 2003;98:S2-S7.

$\checkmark 5$ Galmiche JP, des Varannes SB: Endoscopynegative reflux disease. Curr Gastroenterol Rep 2001;3:206-214.

-6 Fujiwara Y, Takahashi S, Arakawa T, Sollano JD, Zhu Q, Kachintorn U, Rani AA, Hahm KB, Joh T, Kinoshita Y, Matsumoto T, Naito Y, Takeuchi K, Furuta K, Terano A: A 2008 questionnaire-based survey of gastroesophageal reflux disease and related diseases by physicians in East Asian countries. Digestion 2009; 80:119-128.

7 Dean BB, Gano AD Jr, Knight K, Ofman JJ, Fass R: Effectiveness of proton pump inhibitors in nonerosive reflux disease. Clin Gastroenterol Hepatol 2004;2:656-664.

$>8$ Uemura N, Inokuchi H, Serizawa H, Chikama T, Yamauchi M, Tsuru T, Umezu T, Urata T, Yurino N, Tanabe S, Yoshida T, Kawamura S, Murakami A, Yamamoto M, Chiba T: Efficacy and safety of omeprazole in Japanese patients with nonerosive reflux disease. J Gastroenterol 2008;43:670-678.

-9 Miwa H, Sasaki M, Furuta T, Koike T, Habu Y, Ito M, Fujiwara Y, Wada T, Nagahara A, Hongo M, Chiba T, Kinoshita Y: Efficacy of rabeprazole on heartburn symptom resolution in patients with non-erosive and erosive gastro-oesophageal reflux disease: a multicenter study from Japan. Aliment Pharmacol Ther 2007;26:69-77.

10 Fass R, Sifrim D: Management of heartburn not responding to proton pump inhibitors. Gut 2009;58:295-309.

11 Leite LP, Johnston BT, Barrett J, Castell JA, Castell DO: Ineffective esophageal motility (IEM): the primary finding in patients with nonspecific esophageal motility disorder. Dig Dis Sci 1997;42:1859-1865.

12 Castell J, Gideon RM, Castell DO: Esophagus; in Schuster MM (ed): Atlas of Gastrointestinal Motility in Health and Disease. Baltimore, Williams and Wilkins, 1993, pp 134-157.
13 Bredenoord AJ, Tutuian R, Smout AJ, Castell DO: Technology review: esophageal impedance monitoring. Am J Gastroenterol 2007; 102:187-194.

14 Roman S, Bruley des Varannes S, Pouderoux P, Chaput U, Mion F, Galmiche JP, Zerbib F: Ambulatory 24-h oesophageal impedance$\mathrm{pH}$ recordings: reliability of automatic analysis for gastro-oesophageal reflux assessment. Neurogastroenterol Motil 2006;18:978-986.

15 Wiener GJ, Richter JE, Copper JB, Wu WC, Castell DO: The symptom index: a clinically important parameter of ambulatory 24-hour esophageal pH monitoring. Am J Gastroenterol 1988;83:358-361.

-16 Kusano M, Shimoyama Y, Sugimoto S, Kawamura O, Maeda M, Minashi K, Kuribayashi S, Higuchi T, Zai H, Ino K, Horikoshi T, Sugiyama T, Toki M, Ohwada T, Mori M: Development and evaluation of FSSG: frequency scale for the symptoms of GERD. J Gastroenterol 2004;39:888-891.

17 Brodman K, Erdmann AJ, Wolf HG: Cornell Medical Index Health Questionnaire Manual. New York, Cornell University Medical College, 1956.

18 Savarino E, Zentilin P, Tutuian R, Pohl D, Casa DD, Frazzoni M, Cestari R, Savarino V: The role of nonacid reflux in NERD: lessons learned from impedance-pH monitoring in 150 patients off therapy. Am J Gastroenterol 2008;103:2685-2693.

19 Savarino E, Tutuian R, Zentilin P, Dulbecco P, Pohl D, Marabotto E, Parodi A, Sammito G, Gemignani L, Bodini G, Savarino V: Characteristics of reflux episodes and symptom association in patients with erosive esophagitis and nonerosive reflux disease: study using combined impedance-pH off therapy. Am J Gastroenterol 2010;105:1053-1061.

20 Fass R, Dickman R: Non-cardiac chest pain: an update. Neurogastroenterol Motil 2006;18: 408-417.

21 Kohata Y, Fujiwara Y, Machida H, Okazaki H, Yamagami H, Tanigawa $\mathrm{T}$, Watanabe $\mathrm{K}$, Watanabe T, Tominaga K, Arakawa T: Pathogenesis of proton-pump inhibitor-refractory non-erosive reflux disease according to multichannel intraluminal impedance-pH monitoring. J Gastroenterol Hepatol 2012;27(suppl 3):58-62.

22 Waterman DC, Dalton CB, Ott DJ, Castell JA, Bradley LA, Castell DO, Richter JE: Hypertensive lower esophageal sphincter: what does it mean? J Clin Gastroenterol 1989;11:139146.
23 Peng S, Xiao YL, Cui Y, Lin JK, Zhang N, Hu PJ, Chen MH: High-dose esomeprazole is required for intraesophageal acid control in gastroesophageal reflux disease patients with hiatus hernia. J Gastroenterol Hepatol 2012;27: 893-898.

24 Achem AC, Achem SR, Stark ME, DeVault KR: Failure of esophageal peristalsis in older patients: association with esophageal acid exposure. Am J Gastroenterol 2003;98:35-39.

25 Ho SC, Chang CS, Wu CY, Chen GH: Ineffective esophageal motility is a primary motility disorder in gastroesophageal reflux disease. Dig Dis Sci 2002;47:652-656.

26 Hong SJ, Ko BM, Jung IS, Ryu CB, Moon JH, Cho JY, Kim JO, Lee JS, Lee MS, Shim CS, Kim BS: Relevance of ineffective esophageal motility and hyperactive acid sensitization in patients with gastroesophageal reflux. J Gastroenterol Hepatol 2007;22:1662-1665.

27 Foroutan M, Doust HM, Jodeiri B, Derakhshan F, Mohaghegh H, Mousapour H, Poursaadati S, Kiarudi MY, Zali M: Relevance of ineffective esophageal motility with erosive and nonerosive gastroesophageal reflux disease. Indian J Gastroenterol 2008;27:58-61.

28 Lemme EM, Abrahao-Junior LJ, Manhaes Y, Shechter R, Carvalho BB, Alvariz A: Ineffective esophageal motility in gastroesophageal erosive reflux disease and in nonerosive reflux disease: are they different? J Clin Gastroenterol 2005;39:224-227.

29 Tutuian R, Castell DO: Clarification of the esophageal function defect in patients with manometric ineffective esophageal motility: studies using combined impedance-manometry. Clin Gastroenterol Hepatol 2004;2:230236.

30 Savarino E, Gemignani L, Pohl D, Zentilin P, Dulbecco P, Assandri L, Marabotto E, Bonfanti D, Inferrera S, Fazio V, Malesci A, Tutuian R, Savarino V: Oesophageal motility and bolus transit abnormalities increase in parallel with the severity of gastro-oesophageal reflux disease. Aliment Pharmacol Ther 2011; 34:476-486.

31 Knight RE, Wells JR, Parrish RS: Esophageal dysmotility as an important co-factor in extraesophageal manifestations of gastroesophageal reflux. Laryngoscope 2000;110:14621466.

32 Savarino E, Marabotto E, Zentilin P, Frazzoni M, Sammito G, Bonfanti D, Sconfienza L, Assandri L, Gemignani L, Malesci A, Savarino V: The added value of impedance- $\mathrm{pH}$ monitoring to Rome III criteria in distinguishing functional heartburn from non-erosive reflux disease. Dig Liver Dis 2011;43:542-547. 